\title{
Epidemiology and Management Challenges in Prolactinomas
}

\author{
Laurent Vroonen Adrian F. Daly Albert Beckers \\ Department of Endocrinology, Centre Hospitalier Universitaire de Liège, Liège Université, Liège, Belgium
}

\section{Keywords}

Prolactinoma · Epidemiology · Dopamine agonist .

Genetics · Pediatrics · Resistance

\begin{abstract}
Clinically relevant pituitary adenomas are present in about 1 per 1,000 of the general population and prolactinomas are by far the most common clinical subtype of pituitary adenomas. Usually prolactinomas affect premenopausal women and present with typical symptoms of menstrual disturbance and/or galactorrhea. They are generally managed with dopamine agonists to restore fertility and to control symptoms and tumor size. In a subset of prolactinomas, however, management remains challenging. Studies in recent years have identified the factors related to dopamine agonist resistance, such as male sex, genetic features, and aggressive tumor behavior. Certain other patient groups represent particular challenges for management, such as pediatric patients and pregnant women. Treatment with dopamine agonists is usually safe and effective, and adverse effects such as clinically relevant cardiac valvular complications and impulse control disorders may occur in isolated instances. A number of important disease characteristics of prolactinomas remain to be explained, such as the difference in sex prevalence before and after menopause, the
\end{abstract}

higher prevalence of macroadenomas in older males, and the biochemical mechanisms of resistance to dopaminergic agonists.

(c) 2019 S. Karger AG, Basel

\section{Introduction}

Hyperprolactinemia is one of the most common endocrine disorders in clinical practice and usually presents with signs and symptoms that include loss of libido, menstrual/fertility disorders, or galactorrhea [1]. Furthermore, recent evidence suggests that the prevalence of hyperprolactinemia in the community is rising [2]. Various factors can result in prolactin excess (pituitary stalk compression, drug side effects, estrogen, etc.), but pituitary adenomas represent the most clinically important diagnosis. Apart from the common symptoms of hyperprolactinemia, prolactinomas can also be responsible for mechanical compression of local structures leading to visual field disturbance (Fig. 1). Epidemiological studies on pituitary adenomas have shown a much higher prevalence than previously thought, with prolactinomas being the most frequent tumor subtype reported [3-6]. Consequently, prolactinomas will be encountered regularly in the clinical setting. Dopamine agonists are the treatment 


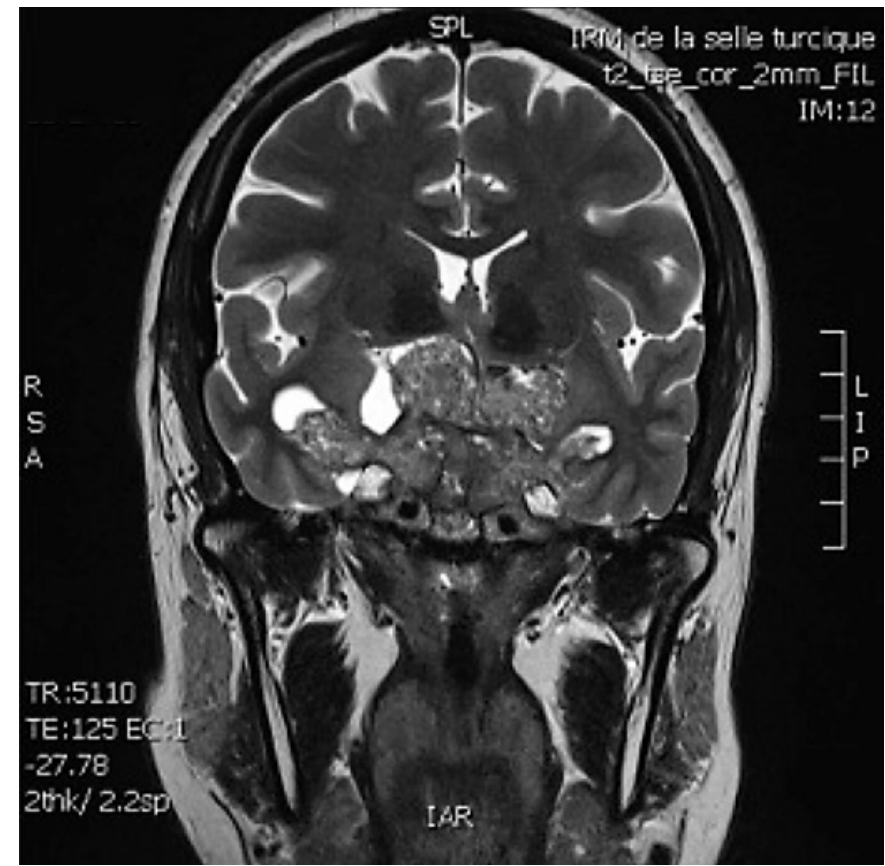

Fig. 1. T2-weighted coronal magnetic resonance image of the brain showing a large, invasive macroprolactinoma with significant suprasellar and extrasellar extension.

of choice for prolactinomas. Cabergoline is widely available and allows for control of prolactin levels and decrease in tumor mass in most cases. In consequence, surgery and radiotherapy are seldom used in the management of prolactinomas, apart from rare aggressive cases or where medical therapy is ineffective or contraindicated. In this review, we provide an update on the clinical presentation and epidemiology of prolactinomas and highlight some existing challenges related to their presentation and management.

\section{Epidemiology}

In 1994, an epidemiological study on the radiological evaluation of pituitary disease in a healthy subject cohort reported a $10 \%$ prevalence of pituitary adenomas [7]. A decade later, Ezzat et al. [8] conducted an in-depth metaanalysis regarding the prevalence of these tumors. That meta-analysis demonstrated a prevalence of $22.5 \%$ in radiological studies and $14.4 \%$ in autopsy series (overall prevalence: $16.7 \%$ ); prolactinomas were the most common subtype (25-41\%) [8]. That finding was confirmed in a subsequent autopsy series of individuals without a

Epidemiology and Management

Challenges in Prolactinomas preexisting pituitary adenoma diagnosis, which found that prolactin-positive immunohistochemical staining was seen in $39.5 \%$ of pituitary adenomas [9]. In that series, the vast majority of tumors were very small microadenomas.

Before 2006, few data were available about the prevalence of pituitary adenomas in the clinical setting. The first study about the prevalence of clinically relevant pituitary adenomas was conducted in the Liège area of Belgium in 2006 [3]. Three distinct districts (rural, suburban, and urban) with a total of 71,972 inhabitants were studied and a pituitary adenoma prevalence of 1 case/1,064 of the population was reported. Of these cases, $66.2 \%$ were prolactinomas, of which $80 \%$ were microprolactinomas $(<10$ $\mathrm{mm}$ diameter) occurring in females. These results were confirmed in different geographical settings thereafter. In 2009 in Switzerland, Fontana and Gaillard [5] found 44 adenomas out of 54,607 inhabitants (prevalence of $1 / 1,241$ ), of which $73 \%$ were women. Once again, prolactinomas predominated ( $56 \%$ of adenomas). Subsequently in the United Kingdom, Fernandez et al. [4] found 63 cases of pituitary adenomas in a population of 81,149 (prevalence 1/1,289), of which 57\% were prolactinomas. Prolactinomas were the more frequent subtype in people under 60 years of age, while non-functioning adenomas were more frequent in those aged $>60$ years of age. Other data from Finland [10] and Malta [6] found similar results and the same proportions of prolactinomas (Table 1). In Sweden, the prevalence was estimated at $1 / 2,688$ inhabitants [11]. Although this confirmed the increased frequency of PA in the general population, these results were lower than other reports. They also found a lower proportion of prolactinomas (32\%) and a higher proportion of non-functioning pituitary adenomas (54\%). This imbalance may be the consequence of the criteria used for considering prolactinomas (prolactin levels $>3$ times the upper limit of normal). The lower prevalence may be also due to a lack of data from general practitioners, as it was a registry-based study. Moreover, they reported a higher prevalence of macroadenomas $(65 \%)$ versus microadenomas $(33 \%)$. In contrast, the pituitary adenoma prevalence in Iceland in 2012 was the highest yet reported (1/865), with $40 \%$ being prolactinomas [12]. Some studies have reported incidence rates for pituitary adenomas $[6,10,12,13]$. Most report an increase in the incidence over time, possibly indicating improved access to diagnostic tools (such as MRI or hormonal assays) and improved disease recognition. Standardized incidence rates (SIR) for pituitary adenomas range between 4 and 7.39 (Table 2). 
Table 1. Epidemiological studies about the prevalence of pituitary adenomas (PA)

\begin{tabular}{lllclrr}
\hline & Country & Population, $n$ & PA, $n$ & Prevalence & Prolactinoma \\
\hline Daly et al. (2006) & Belgium & 71,972 & 68 & $1 / 1,064$ & $66.2 \%$ & 3 \\
Fontana et al. (2009) & Switzerland & 54,607 & 44 & $1 / 1,241$ & $56 \%$ & 5 \\
Fernandez et al. (2010) & UK & 81,149 & 63 & $1 / 1,289$ & $57 \%$ & 4 \\
Raappana et al (2010) & Finland & $722,000-733,000$ & 355 & $1 / 1,471$ & $51 \%$ & 10 \\
Gruppetta et al. (2013) & Malta & 417,602 & 316 & $1 / 1,321$ & $47 \%$ & $40 \%$ \\
Agustsson et al. (2015) & Iceland & 321,857 & 471 & $1 / 865$ & 12 \\
Fainstein Day et al. (2016) & Argentina & 150,000 & 101 & $1 / 1,030$ & $57.5 \%$ & 13 \\
\hline
\end{tabular}

Table 2. Standardized incidence rates (SIR) (cases/100,000/year) in studies reporting incidence of pituitary adenomas

\begin{tabular}{|c|c|c|c|c|c|c|c|c|c|}
\hline Gruppetta et al. & 316 & 4.27 & 2.05 & 1.79 & 0.31 & 0.07 & 0.04 & 6.58 & 2.08 \\
\hline Raappana et al. & 355 & 4 & 2.2 & 1 & 0.34 & 0.17 & 0.03 & 5.9 & 2.2 \\
\hline Agustsson et al. & 471 & 5.8 & $3.6(\mathrm{~F}), 1.4(\mathrm{M})$ & $2.2(\mathrm{~F}), 2.6(\mathrm{M})$ & $0.4(\mathrm{~F}), 0.8(\mathrm{M})$ & & & & \\
\hline Fainstein Day et al. & 101 & 7.39 & 5.41 & 0.65 & 0.92 & 0.4 & & 5.85 & 1.54 \\
\hline
\end{tabular}

\section{Gender Differences}

In a retrospective study of approximately 2,230 patients that had undergone surgery for a pituitary adenoma, Mindermann and Wilson [14] reported that prolactinomas were the most frequent tumor subtype seen (39\%). They highlighted an important difference in prolactinoma prevalence by sex and age. They reported a female-to-male sex ratio for prolactinomas of 10:1 between 18 years of age and the fifth decade of life, while after this age, the ratio was 1:1 [15]. In 2009, Kars et al. [16] focused their attention on hyperprolactinemic patients treated using dopamine agonists. They reported a clearly higher incidence rate in women aged 25-34 compared to men, while this difference disappeared after menopause. In contrast, no specific peak in incidence rate was found in men. Similarly, evaluation of SIR in Iceland found the same discrepancy between sexes, with a median peak in incidence that was significantly younger in women than in men (32 versus 47 years of age, respectively) [12].

To date, this sex difference has not been fully explained, although some factors have been suggested. One such factor is the expression of estrogen receptors (ER) in prolactinomas. An immunocytochemistry study performed in 42 pituitary adenomas revealed a higher prevalence of ER in prolactinomas compared with other subtypes [17]; ER are also strongly expressed in normal and adenomatous lactotroph pituitary cells [18]. However, a retrospective study failed to identify a relationship be- tween the use of estrogen-based oral contraception and a higher incidence of prolactinoma [19]. A prospective study in 16 hyperprolactinemic women (8 idiopathic, 8 with prolactinoma) receiving oral contraceptives did not show any significant change in prolactin levels or radiological features of preexisting pituitary adenomas during estrogenic therapy [20]. Moreover, although a case of a de novo prolactinoma developing in a transgender male receiving high doses of estrogen has been reported [21], more recent studies suggest no influence of estrogen in a large cohort of 98 subjects [22].

\section{Genetic Aspects}

$M E N 1$ gene mutations lead to multiple endocrine neoplasia type 1 (MEN1), an autosomal dominant disease characterized by parathyroid adenomas ( $90 \%$ of cases), enteropancreatic neuroendocrine tumors (64\%), and pituitary adenomas (35-40\%). The prevalence of MEN1 is $0.02-0.2 / 1,000$ and about $22 \%$ of cases have a prolactinoma [23]. Compared with non-MEN1 cases, these adenomas show more aggressive behavior, with a preponderance of macroadenomas and a higher resistance to dopamine agonist treatment [24]. Prolactinomas can also occur in an inherited or familial setting as part of familial isolated pituitary adenoma (FIPA) kindreds [25]. Among a small group of prolactinoma patients, germline mutations in the aryl hydrocarbon receptor interacting protein $(A I P)$ gene have been identified either in FIPA families or 
in the sporadic setting [25]. In an international study, we evaluated the prevalence of AIP mutations in 163 large, aggressive, sporadic macroadenomas (mean tumor size: $29.2 \mathrm{~mm}$ ) diagnosed before the age of 30 . An AIP mutation was found in 7/61 prolactinomas (11.5\%) [26]. Pituitary adenomas, including prolactinomas, also form part of the emerging clinical condition of pheochromocytoma-paraganglioma-pituitary adenoma association [27]. These patients can have prolactinomas in combination with pheochromocytomas/paragangliomas, and individual cases have been shown to have germline mutations in genes such as the succinate dehydrogenase complex subunits or mutations/intragenic deletions in $M A X[27,28]$.

\section{Prolactinomas in Special Populations}

\section{Pediatric Patients}

Pituitary adenomas account for $2 \%$ of supratentorial tumors in children, and prolactinomas are the most frequent subtype of adenoma, although they only occur with an incidence of $<0.1 / 1,000,000$ population $[29,30]$. Girls are more frequently affected than boys, with the latter tending to have more macroadenomas [30,31]. Clinical presentation also varies by age and sex. During the prepubertal period, headache, growth failure, and visual field defects are the most frequent signs, while during puberty, galactorrhea, hypogonadism, or pubertal arrest are more characteristic [32]. Salenave et al. [33] reported a large French series of 77 children and adolescents with macroprolactinomas and found twice as many females as males affected. Across the entire population, irrespective of sex, the main presenting signs/symptoms were pubertal delay/disorders, visual effects, and growth problems. As in other populations, tumor size and prolactin secretion were higher in males than in females. In a recent study, a cohort of 27 pediatric prolactinomas was described [34]. Prevalence was higher in girls (sex ratio 2:1), while earlier onset, larger tumor volume, and higher prolactin levels were seen in boys. Except for cases that needed surgical decompression, cabergoline treatment was effective in controlling prolactin levels and decreasing tumor size.

\section{Elderly Patients}

Prolactinomas in patients older than 65 years account for $4-8 \%$ of pituitary adenomas [29], but precise data about their exact prevalence are scarce. A study based on 17 prolactinomas diagnosed in the postmenopausal period reported a majority of macroadenomas (1 microand 12 macroadenomas; 4 giant adenomas). In that se-

Epidemiology and Management

Challenges in Prolactinomas ries, only one giant prolactinoma was resistant to cabergoline (dose of $3 \mathrm{mg} /$ week for 138 months without normalization of prolactin levels) and presented with cavernous sinus invasion, which is a poor prognostic factor for cabergoline responses [35]. Among 14 postmenopausal women with prolactinomas, Shimon et al. [36] reported that most had large tumors $>20 \mathrm{~mm}$ in diameter, but that responses to dopamine agonists were generally good. The effect of menopause on the regression of hyperprolactinemia and microprolactinoma was studied by Karunakaran et al. [37]. They noted that postmenopausal women had a statistically significantly higher chance of spontaneous regression of their hyperprolactinemia than non-menopausal controls.

An important limitation of studies in the elderly is that prolactinoma prevalence is likely to be underestimated as they can have less clear clinical repercussions at that age (libido loss, for instance, could be ascribed to other causes) and this may lead to later presentation. In an autopsy series, Kovacs et al. [38] noted the presence of prolactin-staining microadenomas in $13 \%$ of patients aged over 80 , indicating that many prolactinomas in the elderly may go unrecognized.

\section{Pregnancy}

During pregnancy, physiological hyperplasia of lactotroph cells leads to pituitary hypertrophy and elevation of prolactin levels by up to 10 -fold. Moreover, pregnancy is an important hyperestrogenic state that can also influence the evolution of preexisting prolactinomas. However, the risk of tumor expansion during pregnancy is low in microprolactinomas (2.7\%) and previously treated macroprolactinomas $(4.8 \%)$; tumor expansion is, however, significantly more frequent in untreated macroprolactinomas (22.9\%) [39]. These results suggest the existence of diverse tumor development mechanisms among prolactinomas and it is difficult to predict which tumors will expand during pregnancy. It is recommendable to intensify clinical follow-up in macroadenomas during pregnancy, starting with a visual field evaluation followed by an unenhanced MRI in women experiencing severe headaches [15]. In case of tumor growth, bromocriptine should be considered as the first-line therapy, as it has the largest safety database available and is in line with the Endocrine Society guidelines [15]. Although recent studies suggest that cabergoline has no relevant adverse effects during the first weeks of gestation, medication choice should err on the side of caution [40]. In contrary, the use of quinagolide is contraindicated. Quinagolide use has been evaluated in 176 pregnancies; 24 (14\%) ended in 
spontaneous abortion, nine resulted in fetal malformations, and one was a premature delivery [41]. Considering the possibility of tumor growth during pregnancy [39, 42 ], surgery has been considered as an alternative for macroprolactinomas in women planning pregnancy. However, the success of surgery depends on the tumor dimensions and invasion and the neurosurgical experience, so decisions on choosing surgery or relying on bromocriptine need to be made on a case-by-case basis.

\section{Challenges in Prolactinoma Treatment}

\section{Dopamine Agonist Resistance}

Dopamine agonists are first-line therapy for prolactinomas as they are effective in controlling clinical symptoms, prolactin levels and tumor volume, and they are well tolerated $[43,44]$. Cabergoline has been the treatment of choice for more than 15 years in many countries, as it allows normalization of prolactin in $90 \%$ of patients with microadenomas and in $80 \%$ with macroadenomas at a median weekly dose of $\sim 1.0 \mathrm{mg}[45,46]$. Data about the prevalence of resistance to cabergoline treatment are scarce, as a firm consensus on the definition of such resistance has been lacking. Considering a cabergoline dose of $2 \mathrm{mg}$ per week (the upper labelled clinical dose) as the cut-off for the definition of resistance, we collected a series of 92 patients among 12 different centers [47]. All received cabergoline for at least 6 months at or above the cut-off dose without normalization of prolactin levels. Using this definition, the prevalence of resistance to cabergoline was 3.4\% among centers. Most of these resistant prolactinomas were macroprolactinomas or giant $(>40$ $\mathrm{mm}$ ) adenomas (82.6\%) and genetic or hereditary features were seen in $13 \%$. In a cohort of 122 macroprolactinomas, Delgrange et al. [48] reported a low prevalence of resistance as 105 were controlled with a dose of $2.5 \mathrm{mg}$ per week. In that series, cavernous sinus invasion was shown to be a poor prognostic factor for control as it was associated with a 10 -fold risk of resistance. In comparison to dopamine agonist-responsive prolactinomas, men are overrepresented in the dopamine agonist-resistant group.

Among types of dopamine agonists, cabergoline has become the treatment of choice. In one large review of resistance to dopamine agonists, Molitch [49] reported a lower resistance rate for cabergoline compared to bromocriptine. Among 1,022 patients treated with bromocriptine, $76 \%$ achieved normal prolactin levels, while this goal was obtained in $86 \%$ of cases among 612 patients treated with cabergoline [49]. Responses to dopamine ag- onists have been noted to change over time, as it is well known that some patients may, after many years of successful treatment, be able to withdraw temporarily or completely from dopamine agonist therapy $[50,51]$. Patients with successful withdrawal are usually those with normalization on low doses of therapy; among others, recurrence is frequent. Interestingly, even in some cases of initially poor responders to cabergoline (needing $\geq 2 \mathrm{mg}$ / week), chronic therapy followed by careful dose reduction can be associated with stable tumor size [52]. However, in patients on maximal doses of cabergoline with large tumor mass or significant impingement on surrounding structures, dose reduction would not appear to be a safe option.

Neurosurgery is an important treatment option in patients with dopamine agonist resistance that persists despite dose escalation. Before the widespread use of primary dopamine agonist therapy, surgery was the main treatment for micro- and macroprolactinomas [53]. Primary dopamine agonist and surgical treatment of prolactinomas are both associated with good efficacy and safety profiles [54]. Follow-up of surgically managed prolactinomas has shown that initial postoperative control rates can be as high as $60-63 \%$, but that the risk of recurrent hyperprolactinemia can occur in up to a third of cases [55]. Ma et al. [56] recently performed a meta-analysis comparing primary medical and surgical therapies and they concluded that significantly higher long-term disease control was achieved surgically. However, the availability of experienced neurosurgical centers is not uniform globally and many prolactinoma patients will not want or are unsuitable for major neurosurgical intervention.

\section{Cardiac Safety of Dopamine Agonists}

Since the reporting of cardiac valvular problems in patients treated with cabergoline for Parkinson's disease [57], the safety of cabergoline in the treatment of prolactinomas has been evaluated by several groups. The initial studies were retrospective series, beginning in 2008 with a cohort of 102 treated prolactinomas as compared to matched controls. Despite a mean cumulative cabergoline dose of $204 \mathrm{mg}$, we found that no significant valvular disease was noted on echocardiography [58]. Wakil et al. [59] reported similar results in a smaller cohort of $44 \mathrm{pa}-$ tients but with a mean cumulative dose of $311 \mathrm{mg}$. These results were confirmed by three subsequent studies [60$62]$. Only two studies found discordant results. Colao et al. [63] reported significant tricuspid valve regurgitation in a cohort of 50 patients (cumulative cabergoline dose of 
$280 \mathrm{mg}$ ). At the same time, Kars et al. [64] reported a higher prevalence of mild tricuspid regurgitation and aortic valve calcification in treated patients, which were deemed to not be clinically relevant.

The first prospective study on cabergoline in pituitary disease was performed in acromegaly patients. After a follow-up of at least 4 years, treated patients had no increased incidence of valvular disease versus controls [65]. The cohorts of Colao et al. [63] and Kars et al. [64] reported prospective data $[66,67]$. Both concluded that there was a non-significant evolution in valvular status. Recently, we reported a large cohort of 100 patients receiving cabergoline for endocrine disease. The vast majority of our population were, as expected, female (70\%). The median total duration of treatment was $>10$ years (124.5 months) and the median cumulative cabergoline dose was $277.8 \mathrm{mg}$ at last follow-up. None of the patients developed significative changes in valvular status [68]. Based on the results by Colao et al. [63] and Kars et al. [64], particular attention was paid to the tricuspid valve. It is important to note that mild tricuspid regurgitation on echocardiography can be found in up to $70 \%$ of the general population. Only four patients in our patient series had grade 2 tricuspid regurgitation at baseline, versus five patients at last follow-up. According to these prospective data, the use of cabergoline is generally considered safe in the endocrine setting at the prescribed dose range. To date, only three cases of confirmed cabergoline associated valvular disease have been reported. The most recent case concerned a 52-year-old woman with a 25 year history of treatment for a macroprolactinoma. The cumulative dose was much higher than described in prospective studies $(4,192 \mathrm{mg})$. The patient developed severe aortic regurgitation [69].

Another safety issue related to dopamine agonist use in the treatment of hyperprolactinemia is that of pathological impulse control disorder [70, 71]. Like with the cardiac valvular issues described above, this problem was initially characterized in patients treated with dopamine agonists for Parkinson's disease or movement disorders at much higher doses than are used in hyperprolactinemia/prolactinoma treatment. Impulse control disorders seen with dopamine agonists include pathological gambling, compulsive shopping, hypersexuality, binge eating, or the repetitive performance of purposeless mechanical activities (known as "punding") [72]. The etiology of this complex disorder is thought to be related to a hyperdopaminergic state in specific regions of the brain [73]. In Parkinson's disease patients, these impulse control disorders occur in $>13 \%$ of patients [74]. As reviewed recently by Noronha and colleagues [70], in endocrine practice, dopamine agonist-induced impulse control disorder appears to be less frequent than in Parkinson's disease, but proper epidemiological data are clearly lacking. Despite its rarity, when it does occur, the severity of the symptoms can have devastating economic or social consequences for patients and their families, depending on the behavioral manifestation of the disorder. Discontinuation of the dopamine agonist is generally associated with a very rapid disappearance of the unwanted compulsions. Increased awareness of the potential for impulse control disorder is necessary among endocrinologists, and during interactions with patients in the clinic, the opportunity should be taken to discuss this rare but important side effect of an otherwise well-tolerated therapy.

\section{Conclusions}

Hyperprolactinemia due to prolactinoma is a frequent problem in endocrine practice. Epidemiological studies have confirmed a higher prevalence of pituitary adenoma than previously thought, with prolactinomas representing the majority of cases. Epidemiological studies have also highlighted interesting differences between sexes and across age groups, raising the question of the influence of sex hormones in the pathogenesis of prolactinomas. Although treatment with dopamine agonists is usually effective and safe, evaluation of resistant cases has identified some important radiological and epidemiological factors that contribute to poor responses, such as cavernous sinus invasion, male sex, and genetic features. Dopamine agonists are generally well tolerated at the dose ranges used in endocrine practice, but clinicians and patients should be aware of rare potential risks such as impulse control disorders and possibly cardiac valvular disease.
References
1 Colao A, Lombardi G. Growth-hormone and prolactin excess. Lancet. 1998 Oct;352(9138): 1455-61.
2 Soto-Pedre E, Newey PJ, Bevan JS, Greig N, Leese GP. The epidemiology of hyperprolac- tinaemia over 20 years in the Tayside region of Scotland: the Prolactin Epidemiology, Au- dit and Research Study (PROLEARS). Clin Endocrinol (Oxf). 2017 Jan;86(1):60-7.
3 Daly AF, Rixhon M, Adam C, Dempegioti A, Tichomirowa MA, Beckers A. High preva- lence of pituitary adenomas: a cross-sectional study in the province of Liege, Belgium. J Clin Endocrinol Metab. 2006 Dec;91(12):4769-75.

Epidemiology and Management Challenges in Prolactinomas
Neuroendocrinology 2019;109:20-27 DOI: $10.1159 / 000497746$ 
4 Fernandez A, Karavitaki N, Wass JA. Prevalence of pituitary adenomas: a communitybased, cross-sectional study in Banbury (Oxfordshire, UK). Clin Endocrinol (Oxf). 2010 Mar;72(3):377-82.

5 Fontana E, Gaillard R. [Epidemiology of pituitary adenoma: results of the first Swiss study]. Rev Med Suisse. 2009 Oct;5(223):2172-4.

6 Gruppetta M, Mercieca C, Vassallo J. Prevalence and incidence of pituitary adenomas: a population based study in Malta. Pituitary. 2013 Dec;16(4):545-53.

7 Hall WA, Luciano MG, Doppman JL, Patronas NJ, Oldfield EH. Pituitary magnetic resonance imaging in normal human volunteers: occult adenomas in the general population. Ann Intern Med. 1994 May;120(10):817-20.

8 Ezzat S, Asa SL, Couldwell WT, Barr CE, Dodge WE, Vance ML, et al. The prevalence of pituitary adenomas: a systematic review. Cancer. 2004 Aug;101(3):613-9.

9 Buurman H, Saeger W. Subclinical adenomas in postmortem pituitaries: classification and correlations to clinical data. Eur J Endocrinol. 2006 May;154(5):753-8.

10 Raappana A, Koivukangas J, Ebeling T, Pirilä $T$. Incidence of pituitary adenomas in Northern Finland in 1992-2007. J Clin Endocrinol Metab. 2010 Sep;95(9):4268-75.

11 Tjörnstrand A, Gunnarsson K, Evert M, Holmberg E, Ragnarsson O, Rosén T, Filipsson Nyström H. The incidence rate of pituitary adenomas in western Sweden for the period 2001-2011. Eur J Endocrinol. 2014 Oct; 171(4):519-26.

12 Agustsson TT, Baldvinsdottir T, Jonasson JG Olafsdottir E, Steinthorsdottir V, Sigurdsson G, Thorsson AV, Carroll PV, Korbonits M, Benediktsson R. The epidemiology of pituitary adenomas in Iceland, 1955-2012: a nationwide population-based study. Eur J Endocrinol. 2015 Nov;173(5):655-64.

13 Day PF, Loto MG, Glerean M, Picasso MF, Lovazzano S, Giunta DH. Incidence and prevalence of clinically relevant pituitary adenomas: retrospective cohort study in a Health Management Organization in Buenos Aires, Argentina. Arch Endocrinol Metab. 2016 Nov-Dec;60(6):554-61.

14 Mindermann T, Wilson CB. Age-related and gender-related occurrence of pituitary adenomas. Clin Endocrinol (Oxf). 1994 Sep;41(3) 359-64.

15 Colao A, Sarno AD, Cappabianca P, Briganti F, Pivonello R, Somma CD, Faggiano A, Biondi B, Lombardi G. Gender differences in the prevalence, clinical features and response to cabergoline in hyperprolactinemia. Eur J Endocrinol. 2003 Mar;148(3):325-31.

16 Kars M, Souverein PC, Herings RM, Romijn JA, Vandenbroucke JP, de Boer A, et al. Estimated age- and sex-specific incidence and prevalence of dopamine agonist-treated hyperprolactinemia. J Clin Endocrinol Metab. 2009 Aug;94(8):2729-34
17 Burdman JA, Pauni M, Heredia Sereno GM, Bordón AE. Estrogen receptors in human pituitary tumors. Horm Metab Res. 2008 Aug; 40(8):524-7.

18 Stefaneanu L, Kovacs K, Horvath E, Lloyd RV, Buchfelder M, Fahlbusch R, et al. In situ hybridization study of estrogen receptor messenger ribonucleic acid in human adenohypophysial cells and pituitary adenomas. J Clin Endocrinol Metab. 1994 Jan;78(1):83-8.

19 Maheux R, Jenicek M, Cleroux R, Beauregard H, De Muylder X, Gratton NM, et al. Oral contraceptives and prolactinomas: a casecontrol study. Am J Obstet Gynecol. 1982 May;143(2):134-8.

20 Testa G, Vegetti W, Motta T, Alagna F, Bianchedi D, Carlucci C, et al. Two-year treatment with oral contraceptives in hyperprolactinemic patients. Contraception. 1998 Aug; 58(2):69-73.

21 Kovacs K, Stefaneanu L, Ezzat S, Smyth HS. Prolactin-producing pituitary adenoma in a male-to-female transsexual patient with protracted estrogen administration. A morphologic study. Arch Pathol Lab Med. 1994 May; 118(5):562-5.

22 Bisson JR, Chan KJ, Safer JD. Prolactin levels do not rise among transgender women treated with estradiol and spironolactone. Endocr Pract. 2018 Jul;24(7):646-51.

23 Brandi ML, Gagel RF, Angeli A, Bilezikian JP, Beck-Peccoz P, Bordi C, et al. Guidelines for diagnosis and therapy of MEN type 1 and type 2. J Clin Endocrinol Metab. 2001 Dec;86(12): 5658-71.

24 Vergès B, Boureille F, Goudet P, Murat A, Beckers A, Sassolas G, et al. Pituitary disease in MEN type 1 (MEN1): data from the FranceBelgium MEN1 multicenter study. J Clin Endocrinol Metab. 2002 Feb;87(2):457-65.

25 Daly AF, Beckers A. Familial isolated pituitary adenomas (FIPA) and mutations in the aryl hydrocarbon receptor interacting protein (AIP) gene. Endocrinol Metab Clin North Am. 2015 Mar;44(1):19-25.

26 Tichomirowa MA, Barlier A, Daly AF, Jaffrain-Rea ML, Ronchi C, Yaneva M, Urban JD, Petrossians P, Elenkova A, Tabarin A, Desailloud R, Maiter D, Schurmeyer T, Cozzi R, Theodoropoulou M, Sievers C, Bernabeu I, Naves LA, Chabre O, Montanana CF, Hana V, Halaby G, Delemer B, Aizpun JI, Sonnet E, Longas AF, Hagelstein MT, Caron P, Stalla GK, Bours V, Zacharieva S, Spada A, Brue T, Beckers A. High prevalence of AIP gene mutations following focused screening in young patients with sporadic pituitary macroadenomas. Eur J Endocrinol. 2011 Oct;165(4):50915.

27 Xekouki P, Szarek E, Bullova P, Giubellino A, Quezado M, Mastroyannis SA, et al. Pituitary adenoma with paraganglioma/pheochromocytoma (3PAs) and succinate dehydrogenase defects in humans and mice. J Clin Endocrinol Metab. 2015 May;100(5):E710-9.
28 Daly AF, Castermans E, Oudijk L, Guitelman MA, Beckers P, Potorac I, et al. Pheochromocytomas and pituitary adenomas in three patients with MAX exon deletions. Endocr Relat Cancer. 2018 May;25(5):L37-42.

29 Ciccarelli A, Daly AF, Beckers A. The epidemiology of prolactinomas. Pituitary. 2005; 8(1):3-6.

30 Colao A, Loche S, Cappa M, Di Sarno A, Landi ML, Sarnacchiaro F, et al.; Clinical Presentation and Long-Term Follow-Up. Prolactinomas in children and adolescents. Clinical presentation and long-term follow-up. J Clin Endocrinol Metab. 1998 Aug;83(8):2777-80.

31 Fideleff HL, Boquete HR, Suárez MG, Azaretzky $M$. Prolactinoma in children and adolescents. Horm Res. 2009;72(4):197-205.

32 Lafferty AR, Chrousos GP. Pituitary tumors in children and adolescents. J Clin Endocrinol Metab. 1999 Dec;84(12):4317-23.

33 Salenave S, Ancelle D, Bahougne T, Raverot G, Kamenický P, Bouligand J, et al. Macroprolactinomas in children and adolescents: factors associated with the response to treatment in 77 patients. J Clin Endocrinol Metab. 2015 Mar; 100(3):1177-86

34 Hoffmann A, Adelmann S, Lohle K, Claviez A, Müller HL. Pediatric prolactinoma: initial presentation, treatment, and long-term prognosis. Eur J Pediatr. 2018 Jan;177(1):125-32.

35 Delgrange E, Duprez T, Maiter D. Influence of parasellar extension of macroprolactinomas defined by magnetic resonance imaging on their responsiveness to dopamine agonist therapy. Clin Endocrinol (Oxf). 2006 Apr; 64(4):456-62.

36 Shimon I, Bronstein MD, Shapiro J, Tsvetov G, Benbassat C, Barkan A. Women with prolactinomas presented at the postmenopausal period. Endocrine. 2014 Dec;47(3):889-94.

37 Karunakaran S, Page RC, Wass JA. The effect of the menopause on prolactin levels in patients with hyperprolactinaemia. Clin Endocrinol (Oxf). 2001 Mar;54(3):295-300.

38 Kovacs K, Ryan N, Horvath E, Singer W, Ezrin C. Pituitary adenomas in old age. J Gerontol. 1980 Jan;35(1):16-22.

39 Molitch ME. Prolactinoma in pregnancy. Best Pract Res Clin Endocrinol Metab. 2011 Dec; 25(6):885-96.

40 Auriemma RS, Perone Y, Di Sarno A, Grasso LF, Guerra E, Gasperi M, et al. Results of a single-center observational 10-year survey study on recurrence of hyperprolactinemia after pregnancy and lactation. J Clin Endocrinol Metab. 2013 Jan;98(1):372-9.

41 Webster J. A comparative review of the tolerability profiles of dopamine agonists in the treatment of hyperprolactinaemia and inhibition of lactation. Drug Saf. 1996 Apr;14(4): $228-38$.

42 Divers WA Jr, Yen SS. Prolactin-producing microadenomas in pregnancy. Obstet Gynecol. 1983 Oct;62(4):425-9.

43 Gillam MP, Molitch ME, Lombardi G, Colao A. Advances in the treatment of prolactinomas. Endocr Rev. 2006 Aug;27(5):485-534. 
44 Colao A, Savastano S. Medical treatment of prolactinomas. Nat Rev Endocrinol. 2011 May;7(5):267-78

45 Verhelst J, Abs R, Maiter D, van den Bruel A, Vandeweghe M, Velkeniers B, et al. Cabergoline in the treatment of hyperprolactinemia: a study in 455 patients. J Clin Endocrinol Metab. 1999 Jul;84(7):2518-22.

46 Di Sarno A, Landi ML, Cappabianca P, Di Salle F, Rossi FW, Pivonello R, et al. Resistance to cabergoline as compared with bromocriptine in hyperprolactinemia: prevalence, clinical definition, and therapeutic strategy. J Clin Endocrinol Metab. 2001 Nov;86(11):525661.

47 Vroonen L, Jaffrain-Rea ML, Petrossians P, Tamagno G, Chanson P, Vilar L, Borson-Chazot F, Naves LA, Brue T, Gatta B, Delemer B, Ciccarelli E, Beck-Peccoz P, Caron P, Daly AF, Beckers A. Prolactinomas resistant to standard doses of cabergoline: a multicenter study of 92 patients. Eur J Endocrinol. 2012 Nov;167(5):651-62.

48 Delgrange E, Daems T, Verhelst J, Abs R, Maiter D. Characterization of resistance to the prolactin-lowering effects of cabergoline in macroprolactinomas: a study in $122 \mathrm{pa}-$ tients. Eur J Endocrinol. 2009 May;160(5): 747-52.

49 Molitch ME. Pharmacologic resistance in prolactinoma patients. Pituitary. 2005;8(1): 43-52.

50 Colao A, Di Sarno A, Cappabianca P, Di Somma C, Pivonello R, Lombardi G. Withdrawal of long-term cabergoline therapy for tumoral and nontumoral hyperprolactinemia. N Engl J Med. 2003 Nov;349(21):2023-33.

51 Hu J, Zheng X, Zhang W, Yang H. Current drug withdrawal strategy in prolactinoma patients treated with cabergoline: a systematic review and meta-analysis. Pituitary. 2015 Oct; 18(5):745-51.

52 Paepegaey AC, Salenave S, Kamenicky P, Maione L, Brailly-Tabard S, Young J, et al. Cabergoline Tapering Is Almost Always Successful in Patients With Macroprolactinomas. J Endocr Soc. 2017 Feb;1(3):221-30.

53 Hamilton DK, Vance ML, Boulos PT, Laws ER. Surgical outcomes in hyporesponsive prolactinomas: analysis of patients with resistance or intolerance to dopamine agonists. $\mathrm{Pi}$ tuitary. 2005;8(1):53-60.
54 Andereggen L, Frey J, Andres RH, El-Koussy M, Beck J, Seiler RW, et al. 10-year follow-up study comparing primary medical vs. surgical therapy in women with prolactinomas. Endocrine. 2017 Jan;55(1):223-30.

55 Primeau V, Raftopoulos C, Maiter D. Outcomes of transsphenoidal surgery in prolactinomas: improvement of hormonal control in dopamine agonist-resistant patients. Eur J Endocrinol. 2012 May;166(5):779-86.

56 Ma Q, Su J, Li Y, Wang J, Long W, Luo M, et al. The Chance of Permanent Cure for Microand Macroprolactinomas, Medication or Surgery? A Systematic Review and Meta-Analysis. Front Endocrinol (Lausanne). 2018 Oct;9: 636.

57 Nutt JG, Wooten GF. Clinical practice. Diagnosis and initial management of Parkinson's disease. N Engl J Med. 2005 Sep;353(10): 1021-7.

58 Lancellotti P, Livadariu E, Markov M, Daly AF, Burlacu MC, Betea D, Pierard L, Beckers A. Cabergoline and the risk of valvular lesions in endocrine disease. Eur J Endocrinol. 2008 Jul;159(1):1-5.

59 Wakil A, Rigby AS, Clark AL, KallvikbackaBennett A, Atkin SL. Low dose cabergoline for hyperprolactinaemia is not associated with clinically significant valvular heart disease. Eur J Endocrinol. 2008 Oct;159(4):R11-4.

60 Vallette S, Serri K, Rivera J, Santagata P, Delorme S, Garfield N, et al. Long-term cabergoline therapy is not associated with valvular heart disease in patients with prolactinomas. Pituitary. 2009;12(3):153-7.

61 Herring N, Szmigielski C, Becher H, Karavitaki N, Wass JA. Valvular heart disease and the use of cabergoline for the treatment of prolactinoma. Clin Endocrinol (Oxf). 2009 Jan;70(1):104-8

62 Lafeber M, Stades AM, Valk GD, Cramer MJ, Teding van Berkhout F, Zelissen PM. Absence of major fibrotic adverse events in hyperprolactinemic patients treated with cabergoline. Eur J Endocrinol. 2010 Apr;162(4):667-75.

63 Colao A, Galderisi M, Di Sarno A, Pardo M, Gaccione $M$, D'Andrea $M$, et al. Increased prevalence of tricuspid regurgitation in patients with prolactinomas chronically treated with cabergoline. J Clin Endocrinol Metab. 2008 Oct;93(10):3777-84.

64 Kars M, Delgado V, Holman ER, Feelders RA, Smit JW, Romijn JA, et al. Aortic valve calcification and mild tricuspid regurgitation but no clinical heart disease after 8 years of dopamine agonist therapy for prolactinoma. J Clin Endocrinol Metab. 2008 Sep;93(9):3348-56.
65 Maione L, Garcia C, Bouchachi A, Kallel N, Maison P, Salenave S, et al. No evidence of a detrimental effect of cabergoline therapy on cardiac valves in patients with acromegaly. J Clin Endocrinol Metab. 2012 Sep; 97(9):E1714-9.

66 Auriemma RS, Pivonello R, Perone Y, Grasso LF, Ferreri L, Simeoli C, Iacuaniello D, Gasperi M, Colao A. Safety of long-term treatment with cabergoline on cardiac valve disease in patients with prolactinomas. Eur J Endocrinol. 2013 Aug 28;169(3):359-66.

67 Delgado V, Biermasz NR, van Thiel SW, Ewe SH, Marsan NA, Holman ER, et al. Changes in heart valve structure and function in $\mathrm{pa}$ tients treated with dopamine agonists for prolactinomas, a 2-year follow-up study. Clin Endocrinol (Oxf). 2012 Jul;77(1):99-105.

68 Vroonen L, Lancellotti P, Garcia MT, Dulgheru R, Rubio-Almanza M, Maiga I, et al. Prospective, long-term study of the effect of cabergoline on valvular status in patients with prolactinoma and idiopathic hyperprolactinemia. Endocrine. 2017 Jan;55(1):239-45.

69 Caputo C, Prior D, Inder WJ. The Third Case of Cabergoline-Associated Valvulopathy: The Value of Routine Cardiovascular Examination for Screening. J Endocr Soc. 2018 Jul; 2(8):965-9.

70 Noronha S, Stokes V, Karavitaki N, Grossman A. Treating prolactinomas with dopamine agonists: always worth the gamble? Endocrine. 2016 Feb;51(2):205-10.

71 Athanasoulia-Kaspar AP, Popp KH, Stalla GK. Neuropsychiatric and metabolic aspects of dopaminergic therapy: perspectives from an endocrinologist and a psychiatrist. Endocr Connect. 2018 Feb;7(2):R88-94.

72 Weintraub D, David AS, Evans AH, Grant JE, Stacy M. Clinical spectrum of impulse control disorders in Parkinson's disease. Mov Disord. 2015 Feb;30(2):121-7.

73 Vriend C. The neurobiology of impulse control disorders in Parkinson's disease: from neurotransmitters to neural networks. Cell Tissue Res. 2018 Jul;373(1):327-36.

74 Weintraub D, Papay K, Siderowf A; Parkinson's Progression Markers Initiative. Screening for impulse control symptoms in patients with de novo Parkinson disease: a case-control study. Neurology. 2013 Jan;80(2):17680. 